\title{
A Study of the African White Rice Stem Borer (Maliarpha separatella Rag.) Population Density Fluctuations at Mwea Irrigation Scheme in Central Kenya
}

\author{
Kega, V. M. ${ }^{1, *}$, Kasina, $\mathbf{M}^{2}$, Olubayo $\mathrm{F}^{3}$, Nderitu, J. H. ${ }^{3}$ \\ ${ }^{1}$ Rice Programme, Kenya Agricultural and Livestock Research Organization- Mwea, Kenya \\ ${ }^{2}$ Kenya Agricultural and Livestock Research Organization, Sericulture Research Centre, Kenya \\ ${ }^{3}$ Department of Plant Science and Crop Protection, College of Agriculture and Veterinary Services, University of Nairobi, Kenya
}

Copyright@2017 by authors, all rights reserved. Authors agree that this article remains permanently open access under the terms of the Creative Commons Attribution License 4.0 International License

\begin{abstract}
The African white rice stem borer (Maliarpha separatella Ragonot) is a major pest of rice in Kenya. To understand and develop appropriate management packages, its population dynamics were studied at Mwea irrigation scheme in Central Kenya. This was for two wet and two dry periods. Farmer fields located in different parts of the scheme and outside the scheme were sampled every fortnight. Farms sampled represented five water provision schedules (System of Rice intensification (SRI), rain fed, flood irrigated, sporadic irrigation, and fallow period). Five planting regimes (on season, off season double cropping, ratoon, and late planting) and three management styles (controlled by National Irrigation Board (N.I.B), not controlled by N.I.B and out-growers) were studied. During each sampling, a $1 \mathrm{mx} 1 \mathrm{~m}$ quadrant was used randomly and pest counted on all the plants within the quadrant. Results showed that the number of $M$. separatella varied significantly $(p<0.05)$ in the scheme. Pest densities were highest in off season planted rice (13.1). High numbers were also found in Non N.I.B controlled fields with sporadic irrigation (8.1) and the lowest in the N.I.B, fallow (2.5) and this was significant $(p<0.05)$. There were no significant differences in pest infestations on the normal season crop (0.3) and the ratoon crop (0.6) $\mathrm{p}<0.05$ and SRI and conventional irrigated fields $(\mathrm{p}<0.05)$. From the results it is recommended that off season planting of rice be discouraged and that efforts are made to ensure that farmers synchronize planting dates and other cultural practices for the crop, within the scheme and in rice farms outside the scheme.
\end{abstract}

Keywords Maliarpha separatella, Fluctuations, Mwea Irrigation Scheme

\section{Introduction}

Globally rice is one of the most important food crops in the fight against hunger. The total annual production stands at 400 million MT of milled rice [12], it is also the most rapidly growing food source in Africa. It has been suggested that food security in Africa will only be achieved through a sustainable increase in local rice production [14]. Resource-poor farmers in developing countries, who currently rely on rice, lose an estimated $10 \%$ in yield each year because of insect pests [12]. Reports indicate that the African white rice stem borer, Maliapha separatella Rag. is a major rice pest in sub Saharan Africa and islands of Comoros and Madagascar [2],[8]. It is the major species in the major upland rice growing areas of West Africa [1],[14], but in East Africa it is important in lowland irrigated rice. Crop loss yield estimates from Kenya varied from 7-34\% [5], [6]. This was mainly on late planted crop and on the ratoon in the irrigation schemes at Mwea in Central Kenya and Ahero in Nyanza [5], [6] and [15].

The recommendation from National Irrigation Board management (NIB) was to grow a single crop of rice in a year, and then leave the land fallow for the rest of the year [19]. Reports indicate that this system allows for a closed season, the prolonged fallow period favours the exponential increase of natural enemies increasing their effectiveness as biological control agents, the flooding also kills the larvae and pupae and this results in low rice stem borer infestations [3], [8]. However this was not followed and there was continuous cropping of rice in the scheme.

System of Rice Intensification (SRI) is a methodology that involves intermittent wetting and drying of rice paddies, unlike in the conventional rice culture where the rice paddies are permanently under water. In Kenya, it was being piloted on 16 hectares by 10 farmers at Mwea irrigation scheme [11]. However, information of $M$. separatella population dynamics under this system is scanty.

Ratooning is known to give a steady yield for three years under most conditions, for the crops for which it most often is used. However, a ratoon crop extends the crop's 
availability that supports additional pest generations [5], [8]. It has been demonstrated that the synchrony of stem borer generations in rice fields is influenced by the synchrony of rice planting in a rice growing area [3], [8]. It has also been reported that the severity of stem borer infestations increase with increase in intensity of rice cultivation [4]. In studies carried elsewhere, availability of host plant greatly influences stem borer's population dynamics [8]. The pest has a narrow host range, which is limited to cultivated rice and a few wild rice species [8]. Feeding by M. separatella at the tillering stage causes a reduction in plant height and number of filled grains. However, when infested at the booting stage, plant height is not affected but total number of grains per panicle, number of filled grains per panicle, and grain weight are significantly reduced [1]. To see the influence of some of these factors on $M$. separatella distribution, a study was carried out to find out whether there were any hot spots of the pest within the scheme, what periods the pest was most abundant and what factors influenced this distribution. This was at Mwea irrigation scheme in Central Kenya where over $80 \%$ of rice in Kenya is grown.

\section{Materials and Methods}

The study was carried out at Mwea Irrigation Scheme $\left(0^{\circ}\right.$ $\left.40^{\prime} \mathrm{S} ; 37^{\circ} 18^{\prime} \mathrm{E}\right)$. The scheme is located in Kirinyaga County and to the west of Mwea division, in Central province of Kenya. It is in the low altitude agro ecological zone, LM 4 at an altitude of 1,100 to 1200 meters above sea level. The annual rainfall ranges between 350 to 1650 millimeters with an average of $950 \mathrm{~mm}$. The rainfall has bimodal distribution with long rains in March to April, and short rains in October to December. The predominant soil type is black cotton soil with few areas having patches of red volcanic and murram soils [7]. Rice farms were selected with the help of management of Mwea Rice Growers Multi -Purpose Society and represented five water provision schedules (System of Rice intensification (SRI), rain fed, flood irrigated, sporadic irrigation, and fallow period). Five planting regimes (on season, off season double cropping, ratoon, late planting), and three management styles (controlled by National Irrigation Board (N.I.B), not controlled by N.I.B and out-growers) were studied. Description of treatments (irrigation water provision, cropping system and management style) is given in Table 1.

The fields were sampled each fortnight for nine months. This was from 22 September 2010 to 29 June 2011, a period of nine months, which represented two dry and two wet periods. During each sampling, a $1 \mathrm{mx} 1 \mathrm{~m}$ quadrant was used randomly and pest counted on all the plants within the quadrant. Data was also taken on tunneled tillers and panicles with white heads. The number of tunneled tillers at harvest was used to represent $M$. separatella population density.

Tunneled tillers from sampled farms were used to elucidate Maliarpha separatella density. Data was subjected to Analysis of variance (ANOVA) and Tukey's Honestly Significant Difference (HSD) post hoc test $(\mathrm{p}<0.05)$ enabled identification of specific pairs of means between which the differences were statistically significant. This was by use of SPSS version 16.0 for windows [15].

Table 1. Irrigation water provision, cropping system and management style categories at Mwea irrigation scheme during the study from September 2010 to July 2011

\begin{tabular}{|c|c|}
\hline Water provision & Description \\
\hline Flood irrigated & Conventional method at Mwea. Rice grown under continuous flooded condition \\
\hline Sporadic irrigation & $\begin{array}{c}\text { Frequent water shortages and application of irrigation water varied from time and in most cases with } \\
\text { prolonged dry spells. }\end{array}$ \\
\hline System of rice intensification (SRI). & $\begin{array}{l}\text { Alternate wet and dry irrigation. The crop is maintained in semi aerobic conditions during the vegetative } \\
\text { phase, followed by shallow flooding after panicle initiation[11] }\end{array}$ \\
\hline \multicolumn{2}{|l|}{ Cropping system } \\
\hline Main season crop & $\begin{array}{c}\text { Conventional crop which was planted normally and within the main cropping season with the following } \\
\text { cropping sequence (rice-fallow period-rice) }\end{array}$ \\
\hline Double crop & $\begin{array}{l}\text { Rice crop planted immediately after the harvest of the main crop and in most cases was planted late in the } \\
\text { following sequence (rice-rice-rice). }\end{array}$ \\
\hline Ratoon crop & $\begin{array}{l}\text { Main crop was harvested when the stems were still green and stalks cut before the main crop was fully } \\
\text { mature, leaving main crop stubble with 2-3 nodes which sprouted to form the next crop in the following } \\
\text { sequence (rice-ratoon-rice) }\end{array}$ \\
\hline Fallow period & $\begin{array}{l}\text { A single crop of rice was grown in one half of the year and on being harvested, nothing else was planted. } \\
\text { The land was left to lie fallow and animals grazed on the land until the following year [19]. }\end{array}$ \\
\hline \multicolumn{2}{|l|}{ Management style } \\
\hline $\begin{array}{l}\text { Controlled by National Irrigation Board } \\
\text { (N.I.B) }\end{array}$ & $\begin{array}{l}\text { These rice farms were within the formal scheme and the fields were managed as per the recommendation } \\
\text { from NIB where a single crop of rice was grown in a year and the land then left fallow for the rest of the } \\
\text { year. NIB also supplied the farm inputs, milled and marketed rice for the farmers. }\end{array}$ \\
\hline Out-growers & $\begin{array}{l}\text { These paddy fields were to the tail end of the scheme where there was limited irrigation water but the } \\
\text { infrastructure was maintained by NIB }\end{array}$ \\
\hline Not controlled by N.I.B & $\begin{array}{l}\text { Rice fields were outside NIB control and outside the scheme and farmers had introduced a second rice } \\
\text { crop through either by planting a second crop in the year or by ratooning the previous season stubble. }\end{array}$ \\
\hline
\end{tabular}




\section{Results}

Results of the study showed $M$. separatella population density varied significantly $(\mathrm{p}<0.05)$ in the scheme and that there were hot spots of the pest in the scheme. Water provision $(\mathrm{p}=0.001)$ and planting time regimes $(\mathrm{p}=0.001)$ had a significant influence $M$. separatella population density while scheme management $(\mathrm{p}=0.10)$ was of no significance on the pests distribution in the scheme. There was interaction between water provision and time of planting. The highest pest population numbers was in Non N.I.B controlled fields with sporadic irrigation and lowest in the N.I.B controlled, flood irrigated with fallow period and this was significant $(\mathrm{p}<0.05)$ (Table 2).

Table 2. Anova Table for Mean Tunneled Tillers Caused By $M$. separatella in the Various Rice Cultivations Cultural Practices at Mwea Irrigation Scheme

\begin{tabular}{|c|c|c|c|c|c|}
\hline SOURCE & DF & SS & MS & $\mathrm{F}$ & $\mathrm{P}$ \\
\hline Water provision & 4 & 18.71 & 4.68 & 7.12 & $0.001 * * *$ \\
\hline $\begin{array}{c}\text { Time of planting } \\
\text { regime }\end{array}$ & 4 & 16.67 & 4.17 & 6.35 & $0.001 * * *$ \\
\hline $\begin{array}{c}\text { Scheme } \\
\text { management }\end{array}$ & 2 & 3.31 & 1.65 & 2.52 & $0.100 \mathrm{NS}$ \\
\hline $\begin{array}{l}\text { Water provision* } \\
\text { Time of planting }\end{array}$ & 1 & 3.13 & 3.13 & 4.76 & $0.038^{*}$ \\
\hline Total & 11 & 41.82 & & & \\
\hline
\end{tabular}

$* * *$ Highly significant; $* \quad$ Significant at $5 \%$ level NS Not significant
Results of Tukey's paired comparison tests showed that the highest $M$. separatella mean differences occurred where rice had been planted off season in SRI water provision followed by off season crop under the conventional irrigation water provision. There were no significant differences between SRI and conventional rice culture. High $M$. separatella infestations occurred in the off-season planted rice irrespective of whether the rice culture was conventional or SRI (Table 3).

Table 3. Paired Comparison Of Mean Differences For M. separatella Population Density In The Various Rice Cultivation Cultural Practices At Mwea Irrigation Scheme

\begin{tabular}{|c|c|c|c|}
\hline & & $\begin{array}{c}\text { Mean } \\
\text { difference }\end{array}$ & $\mathrm{P}$ \\
\hline Ratoon & Off-season & -1.01 & $0.019 * * *$ \\
\hline SRI & & & \\
\hline Conventional & Off season & -2.83 & $0.001 * * *$ \\
\hline Conventional & Sporadic & -2.30 & $0.060 *$ \\
\hline Conventional & late & 2.27 & $0.014 * * *$ \\
\hline SRI & Conventional & 1.60 & $1.00 \mathrm{NS}$ \\
\hline$* *$ Highly significant; $*$ & \multicolumn{2}{|c|}{ Significant at $5 \%$ level } \\
\hline
\end{tabular}

NS Not significant

Pest density $(\mathrm{p}<0.05)$ was also high in off season planted rice (double crop) and low on ratoon crop (Figure 1).

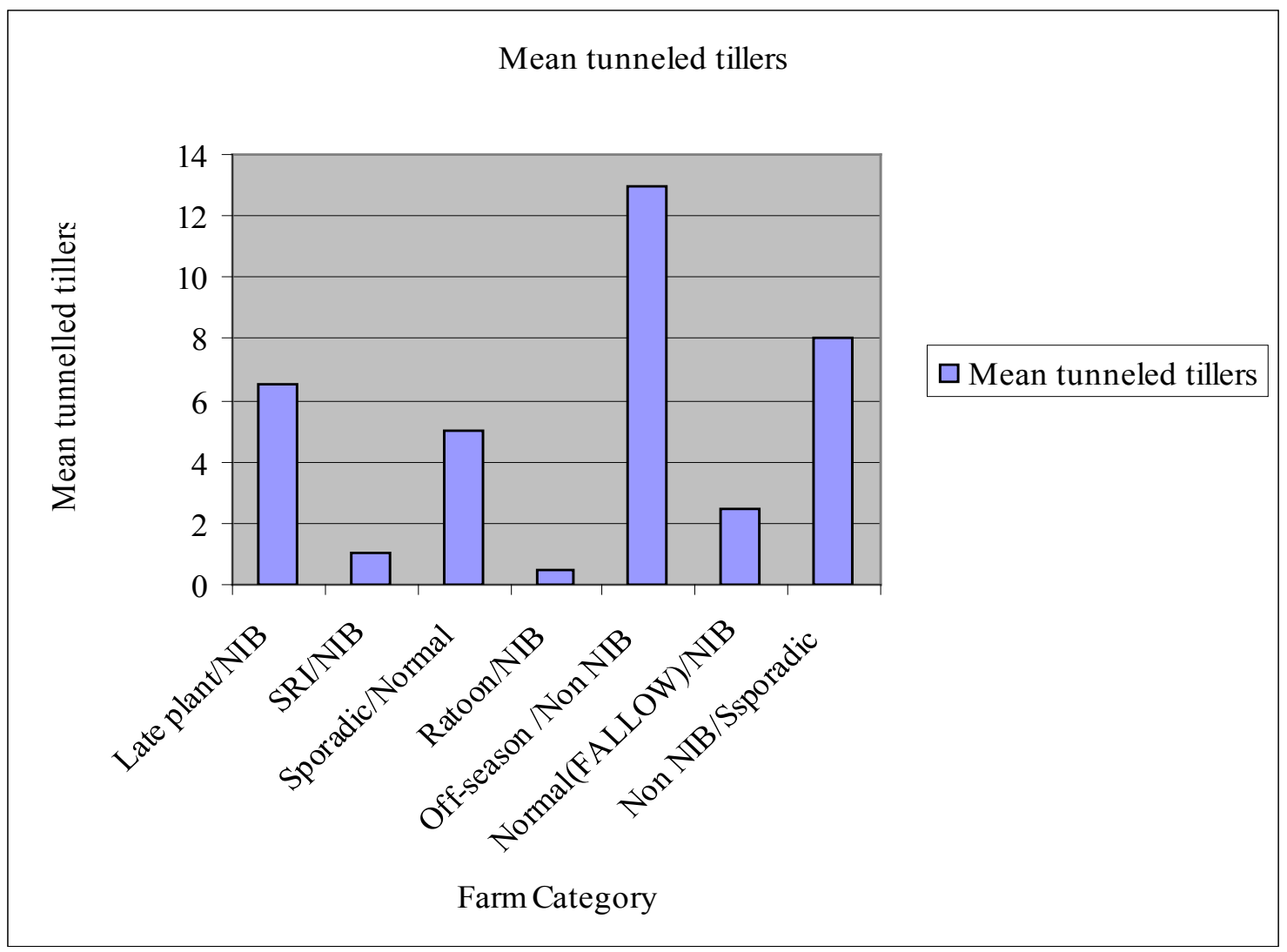

Figure 1. M. separatella Population Density Represented by Mean Number of Tunneled Tillers in the Various Farm Categories at Mwea Irrigation Scheme 
There were significant interactions between water provision management and time of planting $(\mathrm{p}<0.05)$, late planted crop and water provision $(\mathrm{p}=0.001)$ and late planted crop and system of rice intensification (SRI) $(p=0.001)$ indicating that the time of planting was of critical importance in M. separatella fluctuations.

\section{Discussion}

The high pest population numbers in Non N.I.B controlled fields with sporadic irrigation is consistent with reports from Litsinger et al. 2009 who found that rain fed wetland rice system which may be equated with sporadic irrigation at Mwea was more prone to physiological stresses than flood irrigated crop and this minimizes crop compensation and accentuates losses [10]. Expanded growth period also favoured vegetative pests build up in flooded rice cultivation. It has been reported that pest management in irrigated rice production systems is compromised by cultivation practices, such as monoculture of similar varieties, intensive use of chemical inputs (fertilizers and pesticides) and asynchronous planting [2], [5]. These factors are similar to situations in Mwea where farmers grow the aromatic Basmati 370 rice variety which is highly susceptible to insect pests and also use a lot of pesticides and fertilizers. The results from this study are also consistent with reports which show that if a rice-growing area comprises a mixture of farms sown at different times, there will be many oviposition periods, leading to overlapping generations [17]. Litsinger et al. 2009 reported that insect pest damage particularly from stem borers was greater in areas where farmers staggered their planting up to 3 months apart and used a set of varieties that matured in 140-210 days than where farmers planted rice within 1 month, used 120 -d varieties and planted at the start of rainy season [10]. These cultural practices are similar to Mwea where farmers cultivate rice Basmati 370 variety which is has been reported to be susceptible to stem borers.

Non adherence to grow a single crop in a year recommendation by NIB and late planting in some parts of the scheme resulted in the presence of a mosaic of rice farms at different stages of rice crop development throughout the year. The result of this was an increase in intensity of stem borer infestations. These findings are supported by findings of Heinrichs in 1998 which showed that the severity of stem borer infestations increased with increase in intensity of rice cultivation [4].

Kuriah et al. also found out that the growing of a second crop rice crop in a year was technically inefficient [9] and Khan et al., 1990 reported that availability of host plant greatly influenced stem borer's population dynamics [8]. Previous studies indicated that high $M$. separatella populations occurred in late planted rice and on the ratoon [5], [6]. Reports have also been made of low stem borer infestation in rice grown under SRI [18]. However, in this study, very low infestations were found in the ratoon crop and there was no evidence that $M$. separatella population density was lower in the SRI system than in the conventional method of growing paddy rice. The presence of high $M$. separatella infestations in the double crop planted rice irrespective of whether the rice culture was conventional or SRI, underpinned the importance of "double cropping" on stem borer infestations.

\section{Recommendations}

From the above results it is recommended that off season planting of rice be discouraged and that efforts are made to ensure that farmers synchronize planting dates and other cultural practices for the crop, within the scheme and in rice farms outside the scheme. The study also suggests that research is made to identify suitable dry land crops that can be rotated with rice during the year. Efforts must be made to ensure that farmers synchronize planting dates and other cultural practices for the crop, within the scheme and in rice farms outside the scheme. Finally, further studies need to be done to evaluate the effects of ratooning and SRI on pest densities and yields.

\section{Acknowledgements}

The financial support was provided by Director Kenya Agricultural Research Institute (KARI) under the Kenya Agricultural Productivity Project (KAPAP) and a grant under the $2^{\text {nd }}$ call for $\mathrm{PhD}$ and MSC Students from the National Council for Science and Technology (NCST).

\section{REFERENCES}

[1] Akinsola and Agyen-Sampong. 1984. The ecology, bio-ecology and control of rice stem borers in West Africa. Insect Science and its application 5, 69-77

[2] Alam, M. S, John, V. T and Kaung Z. 1985. Insect pests and diseases or rice in Africa. Rice improvement in East, Central and Southern Africa. Proceedings of the International Rice workshop 9-19 April 1984, Lusaka, Zambia pp 91-96

[3] [2\} CABI, 1996. Maliarpha separatella. [Distribution map]. CAB International, Wallingford, UK, Distribution Maps of Plant Pests, December (1st Revision), Map 271 http://www.cabdirect.org/abstracts/20046600271.html. Accessed on 12 September 2012

[4] Dale, D., (1984) Biochemical aspects of varietal resistance to stem borer, Chilo suppressalis (Walker). Final report, The International Rice Research Institute (IRRI) Los Banos, Philippines $33 \mathrm{p}$

[5] Heinrichs, E. A, 1998. Rice: West Africa. In Polaszek A(ed). African cereal stems borer's Economic importance, Taxonomy, Natural enemies and control. CAB International Wallington. Oxon. United Kingdom: 49-57

[6] Ho, D. T. (1984) Stem borer incidence in rice ecosystems in 
Kenya. East Africa. An overview of upland rice research. In Proceedings of the 1982 Bouake, Ivory Coast, Upland rice workshop. International Rice Research Institute (IRRI) Los Banos, Philippines $566 \mathrm{p}$

[7] Ho, D. T, Njokah, J. J and Kibuka, J. G. 1983. Studies of rice stem borers in Kenya with emphasis on Maliarpha separatella Rag Insect Sci Appl 4, 65-73

[8] Jaetzold, R., Schimdt, H.,Hornetz, B. and Chisanya, C. 2006. Kirinyaga District Agroecological zones and subzones. Ministry of Agriculture, Farm management Hand book of Kenya Vol. II. Natural conditions and Farm management information $2^{\text {nd }}$ Edition Part B, Central Kenya, Sub part B2, Central Province: 434-438

[9] Khan Z. R., Litsinger J.A., Barrion A. T., Villanueva F.F.D, Fernadez N.J., Taylor L.D. 1990. World bibliography of rice stem borers 1794-1990 IRRI 1991 pp 415

[10] Kuriah, J.N., Ommeh, H; Kabuage, L., Mbogo, S. and Mutero, C. 2003. Technical efficiency of rice producers in Mwea irrigation scheme. African crop science conference proceedings vol. 6. 668-673

[11] Litsinger, J.A, Canapi, B.L., Bandong, J.P., Lumaban, M.D., Raymundo, F.D. and Barrion, A. T. 2009. Insect pests of rainfed wetland rice in the Philippines: population densities, yield loss, and insecticide management. International Journal of Pest Management 55 (3): 221-242.

[12] Mati, B.M.2009. System of Rice Intensification; growing more with less water promoting the adoption of SRI in Kenya.

\section{IMAWESA Brief notes 6pp}

[13] MOA, 2008. Ministry of Agriculture, Kenya, National rice development strategy 2008-2018:5-7

[14] Njokah, J. J; Kibukah J. G and Raina A. K (1982). Some aspects of population dynamics of Maliarpha separatella $\mathrm{Rag}$ in the Lake Basin area of Kenya. Insect Sci Appl 3, 271-273

[15] Nwilene, F. E, Sanyang, S., Traore, A. K., Goergen, G. and Agunbiade, T. A. 2008. Rice stems borers: Biology, Ecology and Control-Field guide and Technical Manual. Cotonou, Benin, Africa Rice Centre (WARDA) 28p

[16] Statistical package for social scientists (SPSS) (2007) version 16.0 for windows

[17] Suharto, M. and Usyati, N. 2005. Stem borer infestation on rice cultivars at three planting times, The Indonesian Journal of Agricultural Science 2: 39-45.

[18] Umeh, E .D. N., Joshi, R. C and Ukwungwu, M. N. 2000. Biology, status and management of rice insect pests in Nigeria. Crop Protection 11(5): 408-413.

[19] Uphoff N. T. 2007. System of rice intensification (SRI): An efficient, economical and ecologically-friendly way to increase production Pesticide Action Network Asia \& Pacific PANAP Rice sheets, 5-6

[20] Wanjogu, R. K., G. Mugambi, H. L. Adoli, S. O. Shisanya, and M. Tamara. 1995. Mwea Rice Production Manual. NIB Mwea irrigation agricultural development project $48 \mathrm{pp}$. 